\title{
Philosophical aspects of body transplantation
}

\author{
Torbjorn Tannsjo ${ }^{1}$
}

Received: 27 September 2016 / Accepted: 29 September 2016 / Published online: 14 October 2016

(C) Springer-Verlag Wien 2016

Let us assume that it will turn out to be possible to implant a functioning brain in a functioning body from which a dead brain has been removed. Let us assume that this happens, for the first time. The patient wakes up after the operation and screams: "It worked, I survived, I'm alive".

Can we be sure that the patient is right? Has he survived? This is one question a philosopher will raise. A second question is: Does it matter whether the patient has survived or not? Such questions have been addressed by philosophers long before a possibility such as this one had dawned upon us. Here is my personal take on these questions.

I will argue that it is doubtful whether the patient has survived, but that it doesn't matter if he has or has not survived. It is sufficient if the patient who wakes up at the intensive care unit is satisfied with the result and prepared to pay whatever costs are associated with it —rather than that he is tempted to lodge a claim.

Why is it doubtful if the patient has survived? The question boils down to a quest for the meaning of 'personal identity'. What does it mean to say that a person, at one time, and a person at another (later) time, are one and the same?

Some philosophers have insisted that there must be a definite answer to this question. We may speak of them as essentialists with regard to personal identity. Others deny that the question is a genuine one. There may exist many ways of answering it, and some are suitable in some contexts and others are suitable in other contexts. I tend to belong to the latter camp.

Torbjorn Tannsjo

Torbjorn.Tannsjo@philosophy.su.se

1 Department of Philosophy, Stockholm University, 10691 Stockholm, Sweden
Regardless of this deep metaphysical disagreement, there is room for disagreement about detail. Some claim that two persons are identical if they are, in some sense, psychological connected to one another. They share memories, traits of character, and so forth, and they do so because some underlying causal mechanism (they share the same brain, say).

Others claim that persons are organisms (animals). Organisms (animals) such as human beings have memories, traits of character, and so forth, but these may change. They may even go away. Still, the person (the animal) remains alive (such as a person who is brain dead; when he is kept on the ventilator, he is still alive on that account).

On the second (animalist) understanding, it is clear that the person who has received a new body, connected to his brain, has not survived. His memories and traits of character are now localized in a different organism. It is a moot question whether the organism that provided the body has survived or not.

On the former (psychological) understanding of personal identity it may seem reasonable to claim that the person who provided the brain and received the body has survived. However, let us move even further into science fiction. Suppose it is possible to sever the two parts of the brain of the person who has lost his body. Each part is implanted in an available body. Each part of this brain is capable of sustaining life and consciousness. Hence, two persons wake up and scream: "It worked, I survived".

Here they may find that they are somewhat disabled, and yet, they are happy to be alive. How disabled they will turn out to be will depend on the degree of specialization of the different parts of their brains. We may assume a case with minimal specialization. It is way beyond my expertise to speculate any further about this.

If the severing of the two parts of the brain turns out to be outlandish, we can move, as many philosophers - the Oxford philosopher Derek Parfit in particular-have done and 
speculate about a situation where the original brain is scanned, then destroyed, but where the content of it is retained in detail. A new brain, a perfect copy of the original one, is now built and used for transplant purposes. It is placed in an available body. But now we can just as well create two copies of the original brain and place them in two different bodies. Here it is clear that two persons can come to wake up and claim to be the original one. They are both psychologically connected to the 'donor' of the brain (the information contained in it). And, once again, both cannot be right. For simple conceptual reasons, one and the same person cannot exist at different places at the same time, and since there is no reason to think that the claim from one of them is any stronger than the claim from the other, we have to conclude that they are both wrong. None of them is identical to the individual whose brain was scanned.

All of this is sufficient, I think, to suggest that it is far from clear whether the patient in the original example has survived the transplantation. And yet, this doesn't seem to matter, from a practical perspective.

It doesn't matter, I suppose, to the person who chooses to undergo the kind of transplantation here envisaged. Before the operation, the patient is happy to undergo it. After it, the person who wakes up after the operation is happy to be alive. He thinks of himself as a continuation of the earlier one ... and this is what matters. Not whether this belief is true or not. We, the society that provides the service, can adopt a detached objective view. If the operation has worked to the satisfaction of everyone, then it is fine.

However, in the case of a double success, where two persons wake up and claim to be the continuation of the original person, we would have at least a difficult legal situation to tackle. I suppose we could sort it out, however. Perhaps the conflicting parties should be allowed to inherit one-half each of the wealth of the original person. If the original person is married, the marriage should be declared void. Mere personal relations would have to be sorted out in more informal ways, of course, but this is hardly a matter for society to take care of.

Back to the original case with one donated body and one brain used as a graft? Or, should we say that it is the body that works here as the graft? This is a mere terminological matter. However, what about the person whose body we used in the operation? Some philosophers may claim that he has survived. Could his relatives have claims on the person who wakes up and claim that he is their relative?

I think we should avoid this conflict by having the consent to have one's body used for purposes such as these, to include the forfeiture of any such putative rights of one's close ones. 